\title{
Assessment of incidence and risk factors for intensive care acquired delirium in mechanically ventilated patients in surgical intensive care unit - National Hospital of Sri Lanka
}

\author{
P A Nimali Lochanie ${ }^{1 *}$, Nuwan MD Ranawaka ${ }^{2}$ \\ Acting Consultant in Anaesthesiology ${ }^{1 *}$ Lady Ridgeway Hospital for children, Colombo Sri Lanka. \\ Acting Consultant in Critical Care Medicine ${ }^{2}$, National Hospital of Sri Lanka, Colombo, Sri Lanka.
}

\begin{abstract}
Background: Delirium is a common, preventable complication of intensive care unit treatment. It is often under-diagnosed and is an independent predictor of mortality and morbidity. Delirium screening is not a routine practice currently at surgical ICU-NHSL.

Methodology: Patients requiring mechanical ventilation for more than 24 hours at surgical ICU- NHSL were screened for delirium using CAM-ICU score. The potential risk factors contributing to delirium were also studied. Data was analysed using SPSS 17.

Results: Delirium was present in $66.6 \%$ patients. Importantly, the commonest subtype was hypoactive delirium (50\%) while hyperactive and mixed delirium accounted for $30 \%$ and $20 \%$ respectively. Significantly higher proportion of patients who developed delirium were males $(p=0.02)$. There was no association between patients' age and development of delirium. Patients with delirium had a significantly higher incidence of acute liver impairment $(\mathrm{p}=0.03)$, acute malnutrition $(\mathrm{p}=0.05)$ and impaired glycaemic control $(\mathrm{p}=$ $0.05)$. There was a statistically significant association between presence of invasive lines $(\mathrm{p}=0.004)$, use of propofol $(\mathrm{p}=0.006)$ and use of opioids $(0.03)$ and development of delirium.

Conclusion: The study revealed high incidence of delirium in patients who are mechanically ventilated for more than 24 hours. Majority of them were having hypoactive delirium. The need for early identification using routine delirium screening tools and assessment of risk factors contributing to delirium is highlighted.
\end{abstract}

Keywords: Delirium; screening tools; risk factors

\section{Introduction}

Delirium is a common complication of critical illness which has conventionally been regarded as an unavoidable and benign side effect of long term sedation in intensive care units. ${ }^{1}$ However, contrary to popular belief, it is a potentially preventable and reversible condition if identified early and managed effectively.

American Psychiatric Association defines delirium as a disturbance of consciousness, attention, cognition and perception which develops over a short period of time and tends to fluctuate during the course of the day. ${ }^{2}$

Studies conducted in different parts of the world in different intensive care unit (ICU) settings have found an incidence varying from 11 to $80 \%$.

*Correspondence: PA Nimali Lochanie
E mail: lochanie1981@yahoo.co.uk
iD https://orcid.org/0000-0002-4412-7404
Received: $13 / 05 / 2018$
Accepted:04/07/2018
DOI: http://doi.org/10.4038/slia.v26i2.8339
Furthermore, studies suggest a higher incidence of delirium in mechanically ventilated patients. ${ }^{3-}$ 5. Unfortunately, delirium in ICU is often under diagnosed, particularly the hypoactive subtype, as these patients do not exhibit positive symptoms such as agitation. Under diagnosis increases the length of mechanical ventilation, length of ICU stay, cost, incidence of long term cognitive impairment and mortality. ${ }^{1}$

Currently, the pathophysiology of delirium is poorly understood and is believed to be multifactorial. Altered level of dopamine, acetylcholine, tryptophan and phenylalanine are thought to alter the neuronal excitability triggering delirium. Ongoing inflammatory response leading to endothelial damage, thrombin formation and micro vascular compromise and cerebral ischemia leading to diffuse brain injury are other hypothesis contributing to delirium. ${ }^{1}$

There are different study tools available for assessing delirium in ICU. Systematic reviews support Confusion Assessment Method for ICU patients (CAM ICU) as one of the most useful 
assessment tool. ${ }^{6,7}$ It has high sensitivity $(80 \%)$ and specificity $(95 \%)$ for detection of delirium. It takes only about two minutes for a single screening. Thus, it is an excellent diagnostic tool for detection of delirium. ${ }^{8}$

In CAM ICU score, delirium is defined in terms of four diagnostic features.

1. Acute change or fluctuating course of mental status

2. Inattention

3. Altered level of consciousness

4. Disorganized thinking

A patient is diagnosed as having delirium when features 1 and 2 and either feature 3 or 4 are present.

\section{Objectives}

To assess the incidence of and risk factors for delirium in mechanically ventilated patients in surgical ICU of National Hospital of Sri Lanka.

\section{Materials and methods}

\section{Study participants}

A prospective single center study was conducted in surgical ICU - NHSL over a 3-month period (July 2013- September 2013). Surgical ICU is a 9 bedded closed ICU. It offers care for complicated adult post-surgical patients as well as for patients with complex medical issues requiring surgical care. Nurse to patient ratio is $1: 1$. Routine delirium screening is not yet a current practice in the ICU.

Target population was all patients requiring both invasive and non-invasive mechanical ventilation for more than $24 \mathrm{hrs}$ at surgical ICUNHSL. A feasible sample of patients fulfilling inclusion and exclusion criteria during the study duration was selected. Inclusion criteria were all patients requiring mechanical ventilation for more than $24 \mathrm{hrs}$ who are awake or responding to verbal stimuli at surgical ICU-NHSL. Patients with baseline dementia, psychosis, depression, intracranial injury, or ischaemic/haemorrhagic strokes that would confound the evaluation of delirium were excluded.

\section{Study instrument}

Eligible patients were screened daily (between $9.00 \mathrm{am}$ to $11.00 \mathrm{am}$ ) for delirium applying the CAM-ICU score until the day of discharge or death. As the first step Richmond Agitation and Sedation Scale (RASS) was applied. Those having a RASS score of -3 to +4 were taken to step two on whom CAM ICU scale was applied.

Due to the language barrier, screening for inattention was modified from the original score. A string of 10 random numbers with number 1 repeated four times ( $\left.3 \begin{array}{lllllllll}3 & 4 & 6 & 1 & 4 & 1 & 1 & 5 & 8\end{array}\right)$ was used instead of 'SAVE A HAART'. No squeeze for number 1 or squeezing on any number other than number one was considered as an error. If there were two or more errors, patient was considered to be having inattention. Four questions from original CAM ICU questionnaire were directly translated to local language to assess disorganized thinking.

Data pertaining to risk factors contributing for delirium such as chronic medical conditions, acute medical problems, ICU related risk factors and medications were also obtained.

\section{Procedure and statistical analysis}

Assessment of patients was done by one of the authors routinely to eliminate interpreter bias. Data was analyzed statistically using SPSS software. Chi square test was used for nonparametric data while student $t$ test and Mann Whitney U test were used for normally and none normally distributed parametric data respectively.

\section{Ethical considerations}

Ethical approval was granted from the ethical review committee, National hospital of Sri Lanka.

\section{Results}

During the 3-month period, 45 patients required mechanical ventilation for more than $24 \mathrm{hrs} .5$ of them met the exclusion criteria. Out of the remaining 40, CAM ICU score could not be applied for 10 patients because their Richmond Agitation Sedation Scale (RASS) was - 4 or -5 . Ultimately, there were 30 eligible patients on whom CAM ICU score was applicable.

They belonged to an age range of 26 to 76 years with a mean age of $52.5(+/-31.6) .20$ (66.6\%) were males. Most common indication for ICU admission was for post-operative care following major surgery $(46.6 \%)$. Indications for ICU admissions are depicted in Figure 1. 27(87.09\%) were admitted as emergencies. 
Figure 1: Indication for ICU admission

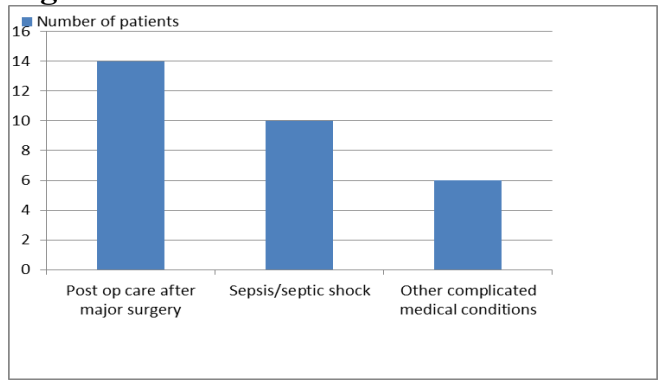

Duration of mechanical ventilation was a positively skewed distribution with a median and a mode of 3 days.

Baseline demographic characteristics of the study population are depicted in Table 1 .

Table 1: Baseline demographic characteristics of the study population

\begin{tabular}{|l|l|l|l|l|}
\hline Variable & $\begin{array}{l}\text { Categori } \\
\text { es }\end{array}$ & $\begin{array}{l}\text { Delirium } \\
\text { present } \\
(\mathbf{n}=\mathbf{2 0})\end{array}$ & $\begin{array}{l}\text { Delirium } \\
\text { absent } \mathbf{( n} \\
\mathbf{= 1 0})\end{array}$ & $\mathbf{p}$ value \\
\hline $\begin{array}{l}\text { Age } \\
\text { (mean in } \\
\text { years) }\end{array}$ & Male & $16(80 \%)$ & $2(20 \%)$ & 0.02 \\
\hline Gender & Female & $4(20 \%)$ & $8(80 \%)$ & 0.33 \\
\hline $\begin{array}{l}\text { Urgency } \\
\text { of } \\
\text { procedure }\end{array}$ & $\begin{array}{l}\text { Emergen } \\
\text { cy }\end{array}$ & $18(90 \%)$ & $8(80 \%)$ & 0.44 \\
\hline Elective & $2(10 \%)$ & $2(20 \%)$ & \\
\hline $\begin{array}{l}\text { Duration } \\
\text { of } \\
\text { ventilation } \\
\text { (median in } \\
\text { days) }\end{array}$ & 4 & 2 & 0.012 \\
\hline
\end{tabular}

Delirium was present in 20/30 (66.6\%) patients. $40 \%$ of the patients who developed delirium were admitted for post-operative care after major surgery. Importantly, the commonest subtype was hypoactive delirium (50\%) while hyperactive and mixed delirium accounted for $30 \%$ and $20 \%$ respectively. (Figure 2 )

Significantly higher number of patients who developed delirium were males $(p=0.02)$. As analysed by Mann -Whitney $U$ test for the positively skewed data set, median duration of mechanical ventilation required was significantly higher in the delirium group $(\mathrm{p}=0.012)$. Age and urgency of admission did not show any association with development of delirium.
Figure 2: Subtypes of delirium

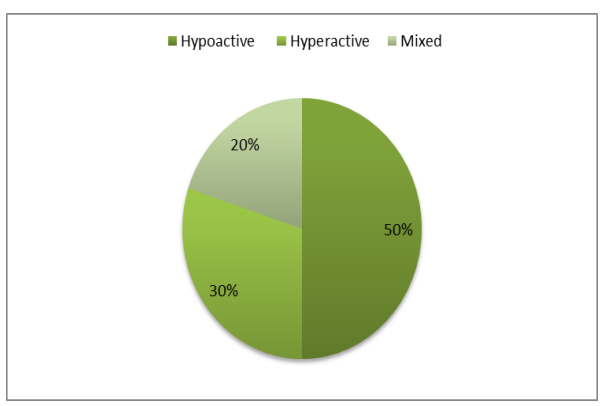

(Hypoactive delirium - RASS score 0 to -3 ; Hyperactive delirium - RASS score +1 to +4 . Mixed - fluctuating RASS score between hypo and hyperactive states)

Comparisons were made between the patients who developed delirium and who did not with regard to 31 potential risk factors. Table 2 illustrates the incidence and their statistical significance using the chi square test. Patients with delirium had a significantly higher incidence of acute liver impairment $(\mathrm{p}=0.03)$, acute malnutrition $(\mathrm{p}=0.05)$, impaired glycaemic control $(p=0.05)$. There was a statistically significant association between presence of invasive lines $(p=0.004)$, use of propofol $(p=$ $0.006)$ and opioids (0.03) for sedation and development of delirium. Among patients with liver impairment, none had hepatic encephalopathy excluded by absence of other neurological signs like asterixis, dysarthria, hyperreflexia, ataxia etc.

Results confirm that the risk factors contributing to delirium are multifactorial.

Table 3: Incidence and statistical significance of risk factors in patients with delirium

\begin{tabular}{|l|l|l|l|l|}
\hline $\begin{array}{l}\text { Risk } \\
\text { factor }\end{array}$ & $\begin{array}{l}\text { Delirium } \\
\text { present } \\
(\mathbf{n = 2 0})\end{array}$ & $\begin{array}{l}\text { Delirium } \\
\text { absent } \\
(\mathbf{n = 1 0 )}\end{array}$ & $\begin{array}{l}\mathbf{p} \\
\text { valu } \\
\text { e }\end{array}$ \\
\hline $\begin{array}{l}\text { Chronic } \\
\text { medical } \\
\text { problems }\end{array}$ & $\begin{array}{l}\text { Multiple } \\
\text { comorbidities }\end{array}$ & $6(30 \%)$ & $4(40 \%)$ & 0.58 \\
\hline & CRF & $2(10 \%)$ & $6(60 \%)$ & 0.3 \\
\hline & Liver disease & 0 & 0 & 0 \\
\hline & $\begin{array}{l}\text { Neurological } \\
\text { diseases }\end{array}$ & $2(10 \%)$ & 0 & 0.3 \\
\hline & $\begin{array}{l}\text { Metabolic } \\
\text { disorders }\end{array}$ & $10(50 \%)$ & $4(40 \%)$ & 0.65 \\
\hline & $\begin{array}{l}\text { Terminal } \\
\text { diseases }\end{array}$ & 0 & 0 & 0 \\
\hline & HIV & 0 & 0 & 0 \\
\hline
\end{tabular}




\begin{tabular}{|c|c|c|c|c|}
\hline & $\begin{array}{l}\text { Visual } \\
\text { impairment }\end{array}$ & $8(40 \%)$ & $4(40 \%)$ & 1 \\
\hline & Social problems & $2(10 \%)$ & 0 & 0.3 \\
\hline & $\begin{array}{l}\text { Chronic alcohol } \\
\text { intake }\end{array}$ & $6(30 \%)$ & $2(20 \%)$ & 0.55 \\
\hline & Smoking & $4(20 \%)$ & $2(20 \%)$ & 1 \\
\hline & Malnutrition & $2(10 \%)$ & 0 & 0.31 \\
\hline & Dehydration & $2(10 \%)$ & 0 & 0.6 \\
\hline \multirow{10}{*}{$\begin{array}{l}\text { Medical } \\
\text { problems } \\
\text { during } \\
\text { acute } \\
\text { presentati } \\
\text { on }\end{array}$} & $\begin{array}{l}\text { Acute } \\
\text { malnutrition }\end{array}$ & $6(30 \%)$ & 0 & 0.05 \\
\hline & $\begin{array}{l}\text { Impaired } \\
\text { glycaemic } \\
\text { control }\end{array}$ & $18(90 \%)$ & $5(50 \%)$ & 0.05 \\
\hline & $\begin{array}{l}\text { Electrolyte } \\
\text { deficiency }\end{array}$ & $16(80 \%)$ & $8(80 \%)$ & 1 \\
\hline & $\begin{array}{l}\text { Liver } \\
\text { impairment }\end{array}$ & $2(10 \%)$ & 0 & 0.03 \\
\hline & $\begin{array}{l}\text { Renal } \\
\text { impairment }\end{array}$ & $8(40 \%)$ & $6(60 \%)$ & 0.3 \\
\hline & $\begin{array}{l}\text { Inotrope } \\
\text { dependence }\end{array}$ & $8(40 \%)$ & $4(40 \%)$ & 1 \\
\hline & Hypoxia & $14(70 \%)$ & $4(40 \%)$ & 0.11 \\
\hline & Sepsis & $12(60 \%)$ & $6(60 \%)$ & 1 \\
\hline & Anxiety & $12(60 \%)$ & $6(60 \%)$ & 1 \\
\hline & Pain & $6(30 \%)$ & $6(60 \%)$ & 0.11 \\
\hline \multirow{4}{*}{$\begin{array}{l}\text { ICU } \\
\text { related }\end{array}$} & Urine catheter & $18(90 \%)$ & $8(80 \%)$ & 0.44 \\
\hline & Invasive lines & 19 & $5(50 \%)$ & $\begin{array}{l}0.00 \\
4\end{array}$ \\
\hline & Restrain & 0 & 0 & 0 \\
\hline & Sleep disorders & 14 & $4(40 \%)$ & 0.11 \\
\hline \multirow{3}{*}{$\begin{array}{l}\text { Drug } \\
\text { related }\end{array}$} & Opioids & 20 & $8(80 \%)$ & 0.03 \\
\hline & $\begin{array}{l}\text { Benzodiazepine } \\
\mathrm{s}\end{array}$ & 0 & 0 & 0 \\
\hline & Propofol & 10 & 0 & $\begin{array}{l}0.00 \\
6\end{array}$ \\
\hline
\end{tabular}

(Definitions - Multiple comorbidities: 2 or more comorbidities; smoking: current or ex smoking: acute malnutrition: 2 or more of insufficient energy intake, weight loss, loss of muscle mass, loss of subcutaneous fat, localized fluid accumulation, reduced hand grip strength ; impaired glycaemic control: capillary blood sugar $>180 \mathrm{mg} / \mathrm{dl}$ on 2 or more readings: acute liver impairment: rise of liver enzymes by 3 times upper normal limits, renal impairment: rise in serum creatinine 1.5 times from baseline or drop in urine output less than $0.5 \mathrm{ml} / \mathrm{kg} /$ hour)

\section{Discussion}

To our knowledge, this is the first study conducted in a Sri Lankan ICU setting to assess incidence and risk factors contributing to ICU acquired delirium. Our study as well as evidence from other parts of the world suggests high incidence of ICU acquired delirium among patients who are mechanically ventilated. $66.6 \%$ of patients who were mechanically ventilated for more than $24 \mathrm{hrs}$ developed delirium at some point of their ICU stay. This incidence is in agreement with the other studies from various other centers across the world. ${ }^{4,-11}$ Importantly, $50 \%$ of them were having hypoactive delirium, which could have been easily missed unless specifically screened for. Under recognition and under documentation of presence of delirium is a common pitfall in many ICUs. ${ }^{12-14}$ Patients with hypoactive delirium are the least likely to survive but those who survive may have better long term function than mixed and hyperactive types. ${ }^{15}$ This highlights the importance of timely detection and treatment of delirium.

CAM- ICU is a validated screening tool for delirium with high sensitivity and specificity. We used a modified version applicable to Sri Lankan setting as original version is meant to be used in an English speaking population. The numerical system was equally simple and was understood and well responded to by our patient population. Thus, it may be a valuable alternative to be used in delirium screening check lists in Sri Lanka.

Significantly higher proportion of patients who developed delirium was male $(\mathrm{p}=0.02)$. Although age has been reported as a significant risk factor outside the ICU, in agreement with other studies, age was not a risk factor in our patient population. ${ }^{4,16,17}$

Median duration of mechanical ventilation required was significantly higher in the delirium group $(\mathrm{p}=0.012)$. This finding is in agreement with the findings from previous studies that mechanical ventilation is an independent predictor of development of delirium. Furthermore, presence of delirium increases the duration of mechanical ventilation. ${ }^{4,9,10}$ Thus, attempting for early extubation with daily awakening and breathing trials is vital.

Risk factors associated with delirium are believed to be multifactorial. Potential risk factors were categorized in to 4 domains chronic medical conditions, acute medical problems, ICU related factors and medications. 
Surprisingly, development of delirium did not show any significant association with chronic medical problems. This may partly be due to the defined patient group where indication for ICU admission in the majority was for post op care after major surgery rather than for severe medical problems.

Significantly higher number of patients with ICU acquired delirium had acute malnutrition, impaired glycaemic control and liver impairment. Our patient population did not show any significant association with other acute risk factors described in the literature.

A statistically significant number of patients $(p=0.04)$ with delirium had invasive lines compared to the non-delirious group. This may partly be due to increased disease severity in this group necessitating more invasive monitoring. Furthermore, presence of invasive lines is a well described risk factor for ICU acquired delirium. ${ }^{4}$

Association between conventional sedatives and delirium is well known, with benzodiazepine showing the strongest association. As benzodiazepines are sparingly used in surgical ICU for sedation, its contribution towards development of delirium could not be analysed. On the other hand, there was a statistically increased incidence of use of propofol and opioids for sedation in the delirium group. Daily sedation holds and awakening and breathing trials are recommended as it allows titration of sedatives and early extubation.

\section{Limitations}

After applying inclusion and exclusion criteria, the total sample size we could gather over the study period (3 months) was 30. A larger sample obtained over an extended duration would have given a better power for the study and a better predictive value on associated risk factors.

CAM ICU score was applied once daily for our patients which is the recommended frequency for delirium screening. However, by definition delirium is an acute onset cerebral dysfunction fluctuating over the course of the day. Thus, we might have missed some patients with delirium.

\section{Recommendations}

Delirium screening and risk assessment should be introduced as a routine clinical practice in the ICU for early identification and treatment.
Delirium screening should be incorporated to ICU flow sheet.

Further large scale studies should be conducted over an extended period of time.

\section{Conclusion}

$66.6 \%$ of patients who were mechanically ventilated for more than $24 \mathrm{hrs}$ developed delirium at some stage of their ICU stay. Majority of them were having hypoactive delirium. This incidence is in agreement with the other international studies.

Early identification using delirium screening tools and assessment of risk factors contributing to delirium plays an imperative role in early detection and appropriate management to achieve a better outcome.

\section{References}

1. Connor D, William English. Delirium in critical care. Updates in Anaesthesia. 2012; 28:67-73. https://www.wfsahq.org/documents/Update

2. American Psychiatric Association practice guidelines for the treatment of psychiatric disorders: Compendium 2006. Pp72-73. https://psychiatryonline.org/guidelines

3. Figueroa-Ramos MI, Arroyo-Novoa CM, Lee KA et al. Sleep and delirium in ICU patients: a review of mechanisms and manifestations. Intensive Care Medicine. 2009; 35(5): 781-795. https://www.deepdyve.com/lp/springerjournals/sleep-and-delirium-in-icu-patients-areview-of-mechanisms-and-HP7wPwXJVL https://doi.org/10.1007/s00134-009-1397-4 PMid:19165463

4. Ouimet S, Kavanagh BP, Gottfried SB et al. Incidence, risk factors and consequences of ICU delirium. Intensive Care Medicine. 2007; 33(1): 66-73. https://www.ncbi.nlm.nih.gov/pubmed https://doi.org/10.1007/s00134-006-0399-8 PMid:17102966

5. Zaal IJ, Devlin JW, Peelen LM et al. A systematic review of risk factors for delirium in the ICU. Critical Care Medicine. 2015;43(1): 4047.

http://journals.lww.com/ccmjournal/Abstract/201 5/01000/A_Systematic_Review_of_Risk_Factor s_for_Delirium.6.aspx

http://onlinelibrary.wiley.com/doi/10.1111/j.153

2-5415.2008.01674.x/full

https://doi.org/10.1097/CCM.0000000000000625 PMid:25251759

6. Wei LA, Fearing MA, Sternberg EJ, Inouye SK. The Confusion Assessment Method: a systematic review of current usage. Journal of the American Geriatric Society. 2008;56: 823-830. 
https://doi.org/10.1111/j.1532-

5415.2008.01674.x

PMid:18384586 PMCid:PMC2585541

7. Wong CL, Holroyd-Leduc J, Simel DL, Straus SE. Does this patient have delirium? Value of bedside instruments. JAMA 2010; 304: 779-786. http://jama.jamanetwork.com/article.aspx https://doi.org/10.1001/jama.2010.1182 PMid:20716741

8. Gusmao-Flores D, Figueira Salluh JI, Chalhub RA, Quarantini LC. The confusion assessment method for the intensive care unit (CAM-ICU) and intensive care delirium screening checklist (ICDSC) for the diagnosis of delirium: a systematic review and meta-analysis of clinical studies. Critical care. 2012; 16: 115. https://www.ncbi.nlm.nih.gov/pubmed/22759376/ https://doi.org/10.1186/cc11407 PMid:22759376 PMCid:PMC3580690

9. E. W. Ely, S. K. Inouye, G. R. Bernard et al. Delirium in mechanically ventilated patients: validity and reliability of the confusion assessment method for the intensive care unit (CAM-ICU). The Journal of the American Medical Association. 2001; 286(21). 2703-10. https://doi.org/10.1001/jama.286.21.2703 PMid:11730446

10. González-López A, AlbaicetaGM, Talbot K. Newly identified precipitating factors in mechanical ventilation-induced brain damage: implications for treating ICU delirium. Expert Review of Neurotherapeutics. 2014; 14(6):58388.

https://doi.org/10.1586/14737175.2014.915743 PMid:24852225

11. Mehta S, Burry L, Cook D et al. Daily sedation interruption in mechanically ventilated critically ill patients cared for with a sedation protocol: a randomized controlled trial. The Journal of the American Medical Association. 2012; 308(19): 1985-92.

https://doi.org/10.1001/jama.2012.13872 PMid:23180503

12. Rockwood K, Cosway S, Stolee $\mathrm{P}$ et al. Increasing the recognition of delirium in elderly patients. Journal of the American Geriatric Society. 1994 ; 42: 252-6.

https://doi.org/10.1111/j.1532$\underline{5415.1994 . t b 01747 . x}$

13. Inouye SK, Foreman MD, Mion LC, Katz KH, Cooney LM Jr. Nurses' recognition of delirium and its symptoms: comparison of nurse and researcher ratings. Archives of Internal Medicine.2001; 161: 2467-73.

https://doi.org/10.1001/archinte.161.20.2467 PMid:11700159

14. Gustafson Y, Brannstrom B, Norberg A, Bucht G, Winblad B: Underdiagnosis and poor documentation of acute confusional states in elderly hip fracture patients. Journal of the
American Geriatric Society. 1991; 39:760-65. https://doi.org/10.1111/j.15325415.1991.tb02697.x

15. Van den Boogard $M$, Schoonhoven Levers AW et al. Delirium in critical ill patients: Impact on long term health related quality of life and cognitive functioning. Critical care medicine. 2012; 40: 112-18.

https://doi.org/10.1097/CCM.0b013e31822e9fc9 PMid:21926597

16. Pisani MA, Murphey TE, Van Nees PH,et al. Characteristics associated with delirium in older patients in a medical intensive care unit. Archives of Internal Medicine.2007; 167:162934.

https://doi.org/10.1001/archinte.167.15.1629 PMid:17698685

17. Van Romphey B, Elseviers MM, Scuurmans MJ et al. Risk factors for delirium in intensive care unit patients: A prospective cohort study. Critical care.2009; 13:R77.

https://doi.org/10.1186/cc7892 PMid:19457226 PMCid:PMC2717440

18. Serafim R, Rodrigo B, Fernando FA, Matt S et al. Pharmacologic prevention and treatment of delirium in intensive care patients: A systematic review. Journal of Critical Care. 2015; 8: 799807.

https://doi.org/10.1016/j.jcrc.2015.04.005 PMid:25957498 